\title{
RNA-Binding Affinities and Crystal Structure of Oligonucleotides Containing Five-Atom Amide-Based Backbone Structures ${ }^{\dagger,+}$
}

\author{
Pradeep S. Pallan,, , Peter von Matt, ${ }^{\mathrm{I}, \#}$ Christopher J. Wilds, ${ }^{\S, \perp}$ Karl-Heinz Altmann,,,$\circ$ and Martin Egli*,§ \\ Department of Biochemistry, School of Medicine, Vanderbilt University, Nashville, Tennessee 37232, Novartis Institute for \\ Biomedical Research, CH-4002 Basel, Switzerland, Department of Chemistry and Biochemistry, Concordia University, \\ Montreal, Quebec H4B 1R6, Canada, and Department of Chemistry and Applied Biosciences, \\ Institute of Pharmaceutical Sciences, Swiss Federal Institute of Technology, CH-8093 Zürich, Switzerland
}

Received February 20, 2006; Revised Manuscript Received May 1, 2006

\begin{abstract}
Among the hundreds of nucleic acid analogues that have been studied over the last two decades only very few exhibit backbones with linkers between residues that are either shorter or longer than the four-atom linker $\mathrm{O}^{\prime}$-P-O5'-C5' connecting sugar ring moieties in DNA and RNA. 2'-Deoxyribonucleoside dimers connected by a five-atom linker $\mathrm{O}^{\prime}-\mathrm{CH} *\left(\mathrm{CH}_{3}\right)-\mathrm{CO}-\mathrm{NH}-\mathrm{CH}_{2}(*$ designates a chiral center) were reported to lead to only a slight destabilization of RNA-DNA hybrids in which the DNA strand contained one or several of these amide-linked dimers (De Napoli, L., Iadonisi, A., Montesarchio, D., Varra, M., and Piccialli, G. (1995) Synthesis of thymidine dimers containing a new internucleosidic amide linkage and their incorporation into oligodeoxyribonucleotides, Bioorg. Med. Chem. Lett. 5, 1647-1652). To analyze the influence of various chemistries of such five-atom amide linkers on the RNA-binding affinity of modified DNA strands, we have synthesized five different amide-linked dimers, including structures with homochiral linkers of the type $\mathrm{X}^{\prime}-\mathrm{C}^{*} \mathrm{H}\left(\mathrm{CH}_{3}\right)-\mathrm{CO}-\mathrm{NH}-\mathrm{CH}_{2}\left(\mathrm{X}=\mathrm{O}, \mathrm{CH}_{2}\right)$ as well as the corresponding analogues carrying methoxy groups at the 2'-position of the $3^{\prime}$-nucleosides. We have conducted a detailed thermodynamic analysis of duplex formation between the modified DNA and RNA, with the DNA strands containing between one and seven consecutive modified dimers. Some of the five-atom-linked dimers lead to significantly higher RNA-binding affinities compared with that of native DNA. Interestingly, the linkers with opposite stereochemistry at the chiral center stabilize duplexes between the modified DNA and RNA to different degrees. CD spectroscopy in solution and a crystal structure of an RNA-DNA duplex with a single amide-linked dimer demonstrate that the longer amide backbones do not disrupt the duplex geometry. These observations provide further evidence that stable cross-pairing between two different types of nucleic acids does not require the numbers of atoms linking their individual residues to match.
\end{abstract}

A vast number of chemically modified nucleic acids have been synthesized over the last years as a part of the efforts to evaluate oligonucleotides as antigene, antisense, and RNA interference agents with potential therapeutic applications

\footnotetext{
Financial support by the US National Institutes of Health is gratefully acknowledged (GM55237 to M.E.). C.J.W. was the recipient of postdoctoral scholarships from the Natural Science and Engineering Research Council of Canada (NSERC) and the Fonds pour la Formation de Chercheurs et l'Aide a la Recherche (FCAR). The use of the Advanced Photon Source was supported by the U.S. Department of Energy, Basic Energy Sciences, Office of Science, under Contract No. W-31-109-Eng-38. The DuPont-Northwestern-Dow Collaborative Access Team (DND-CAT) Synchrotron Research Center at the Advanced Photon Source (Sector 5) is supported by E. I. DuPont de Nemours \& Co., The Dow Chemical Company, the National Science Foundation, and the State of Illinois.

Coordinates and structure factors of the amide-modified RNADNA duplex have been deposited in the Protein Data Bank (http:// www.rcsb.org; pdb ID code 2GUN).

* Corresponding author. Phone: +41 44 633-7390. Fax: +41 44 633-1360. E-mail: karl-heinz.altmann@pharma.ethz.ch (K.-H.A.). Phone: +1 (615) 343-8070. Fax: +1 (615) 322-7122. E-mail: martin.egli@vanderbilt.edu (M.E.).

$\S$ Vanderbilt University.

"Novartis Institute for Biomedical Research.

${ }^{\perp}$ Concordia University.

${ }^{\circ}$ Swiss Federal Institute of Technology.

\# These authors contributed equally.
}

$(1-3)$. As in DNA, the repetitive backbone unit in almost all of these analogues, including PNA (4), contains six atoms. ${ }^{1}$ For example, the repetitive unit in DNA and RNA comprises $\mathrm{P}, \mathrm{O}^{\prime}, \mathrm{C}^{\prime}, \mathrm{C}^{\prime}, \mathrm{C}^{\prime}$, and $\mathrm{O}^{\prime}$ and, thus, a fouratom spacer linking the adjacent five-membered rings ( ${ }^{\prime}$, $\mathrm{P}, \mathrm{O}^{\prime}$, and $\mathrm{C5}^{\prime}$; Figure 1A). Interestingly, analogues with shorter backbones, which are being investigated in the context of an etiology of nucleic acid structure (7), such as threofuranosyl nucleic acid (TNA) $(8,9)$, lyxopyranosyl nucleic acid (LPNA) (10), and glycol nucleic acid (GNA) (11), not only exhibit stable self-pairing but also effective and selective cross-pairing with DNA and RNA. The backbone units of these analogues are all one atom shorter than the natural nucleic acids. These observations demonstrate that duplex formation via Watson-Crick base pairing

\footnotetext{
${ }^{1}$ In the manuscript, the term five-atom refers to the linker between $\mathrm{C}^{\prime}(\mathrm{n})$ and $\mathrm{C}^{\prime}(\mathrm{n}+1)$ from two consecutive nucleotides. The definition of the repetitive backbone unit used here considers only a linear array of atoms. Independent of particular connectivity, atoms or substituents bound to any of the backbone atoms (i.e., O1P and $\mathrm{O} 2 \mathrm{P}$ to $\mathrm{P}$ or substituents at $\mathrm{C}^{\prime}$ in DNA or RNA analogues) are not considered. Thus, the backbones of analogues such as bicyclo-DNA (5) or taloand allo-RNA (6) both feature a six-atom repetitive backbone unit, or, in other words, a four-atom linker between the cyclic sugar moieties from consecutive residues.
} 


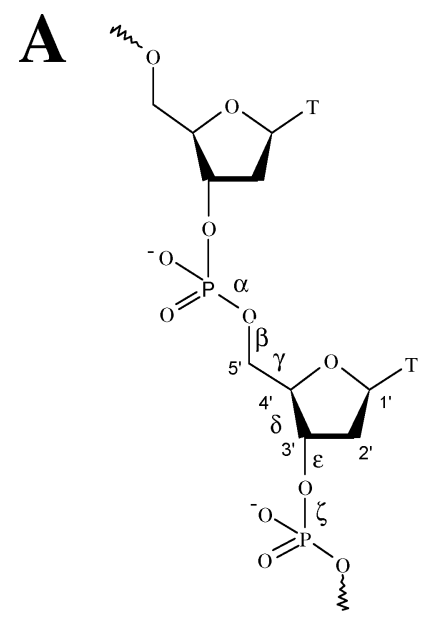

DNA
B

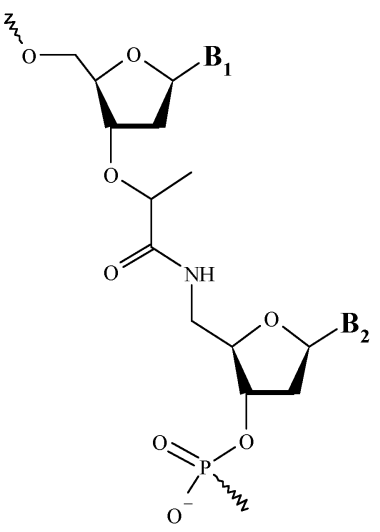

IA

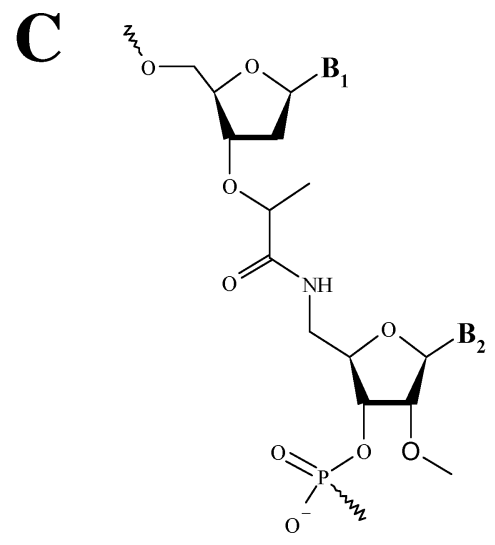

IB
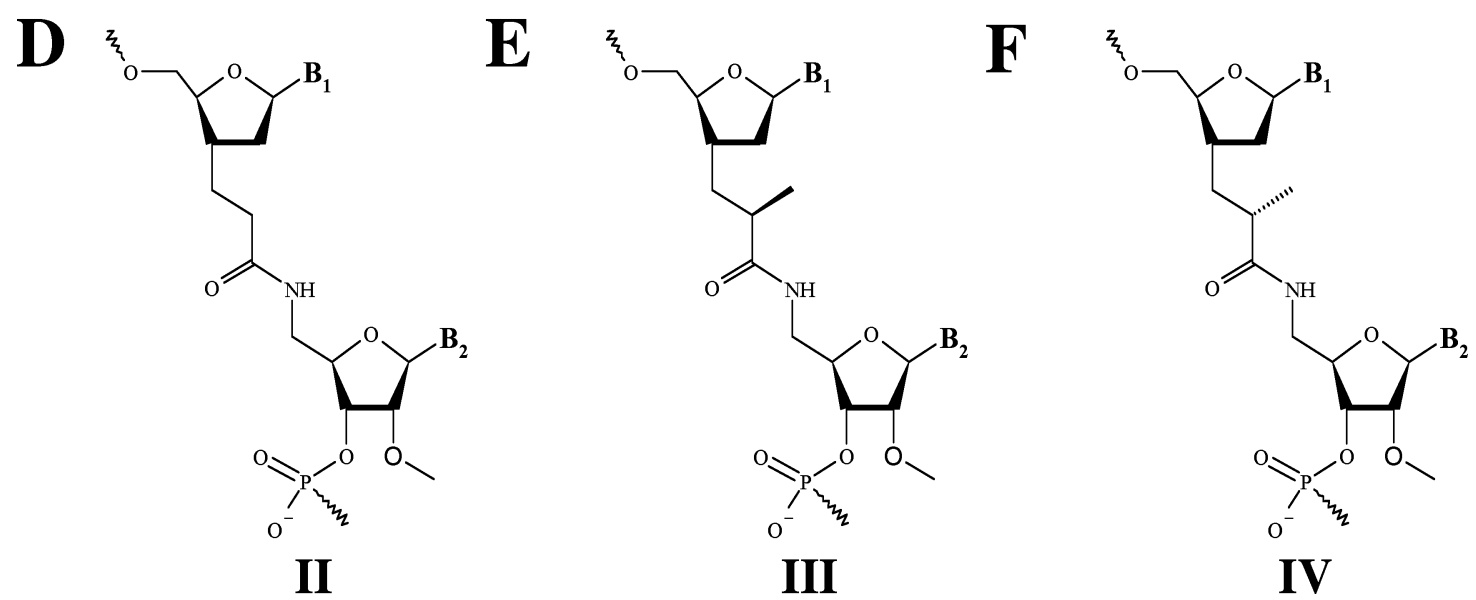

FIGURE 1: Structures of DNA and dimers with various five-atom amide-based linkers in their backbone. (A) DNA, (B) amide type IA, (C) IB, (D) II, (E) III, and (F) IV. Selected DNA atoms are numbered in panel A, and the six backbone torsion angles are labeled.

is not an exclusive attribute of species with backbones composed of six-atom repeat units and that base pairing does not require matching lengths of backbones.

In contrast to analogues with shortened backbones, only very little is known about the consequences of duplex formation of backbone extensions, for example, for DNA analogues with repetitive units containing seven atoms (i.e., five-atom spacers linking cyclic portions of sugars from adjacent residues). Stork and co-workers (12) and De Mesmaeker and co-workers (13) independently showed that analogues with four-atom amide linkers have higher RNA affinity than those with five-atom amide linkers. However, oligonucleotides containing amide $(\mathrm{am})$-linked modified TamT dimers with am = C3'-O-CH* $\left(\mathrm{CH}_{3}\right)-\mathrm{CO}-\mathrm{NH}-\mathrm{CH}_{2}-\mathrm{C}^{\prime}{ }^{\prime}$ (*: either $R$ or $S$ stereochemistry), that is, a five-atom linker structure, were found to have only slightly reduced RNAbinding affinity compared with that of the corresponding unmodified DNAs (14). However, only one sequence with a single modified dimer at the $5^{\prime}$-terminus was investigated in this latter study, thus providing only very limited information on the general effects of this type of modification on RNA-binding affinity.

Prompted by these previous findings and to establish a more rigorous understanding of the relationship between linker structure and hybridization properties of oligonucleotides with extended backbone structures, we have investigated the RNA-binding affinities of oligodeoxyribonucle- otides containing amide-based modified TamT and $\operatorname{Tam}^{M e} \mathrm{C}$ dimers incorporating (homochiral) five-atom linkers of the general structure $-\mathrm{X}^{\prime}-\mathrm{C} * \mathrm{H}(\mathrm{R})-\mathrm{CO}-\mathrm{NH}-\mathrm{CH}_{2}$ (with $\mathrm{X}=\mathrm{O}$, $\mathrm{CH}_{2} ; \mathrm{R}=\mathrm{H}, \mathrm{CH}_{3}$ ) in combination with either unmodified or 2'-methoxy-substituted 2'-deoxyribose units (Figure 1). Modified backbone/sugar structure II represents an extension of previous work by De Mesmaeker et al., who have investigated the same type of backbone modification but in the absence of additional modifications of the sugar moieties (13). We have carried out an extensive analysis of the thermal denaturation of duplexes between modified DNAs containing amide-linked dimers and complementary RNA, which has allowed the derivation of all relevant thermodynamic parameters. ${ }^{2}$ In addition, the conformations of such heteroduplexes were studied using circular dichroism spectroscopy and X-ray crystallography. The X-ray crystal structure determined for a duplex between a DNA nonamer with a single amide-linked $T\left(\mathrm{O}_{3}^{\prime}-(R) \mathrm{CH}\left(\mathrm{CH}_{3}\right)-\mathrm{CO}-\mathrm{NH}-\mathrm{CH}_{2}\right) T$ dimer reveals that the longer backbone is accommodated locally without significant changes in stacking or other helical parameters.

Our work demonstrates for the first time that five-atom amide linkers, when combined with appropriate sugar

${ }^{2}$ A preliminary account of this work has appeared in the proceedings of a conference but did not include any crystallographic data or the detailed thermodynamic analysis of duplex formation (15). 
Scheme $1^{a}$

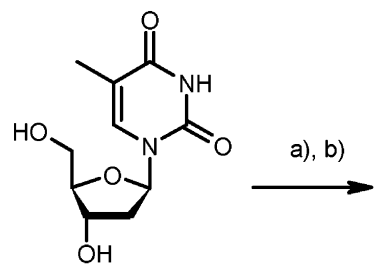<smiles>[R16]n1c(=O)c(C)cn([C@@H]2O[C@@H]3C[C@H]2OC3COC)c1=O</smiles>

6

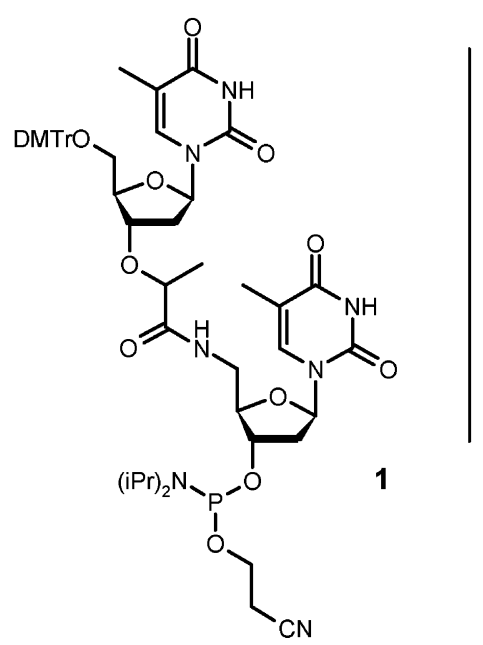

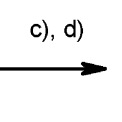<smiles></smiles>

7A/7B

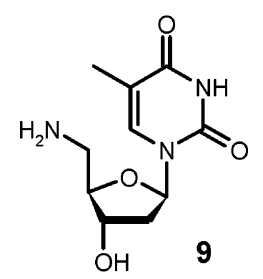

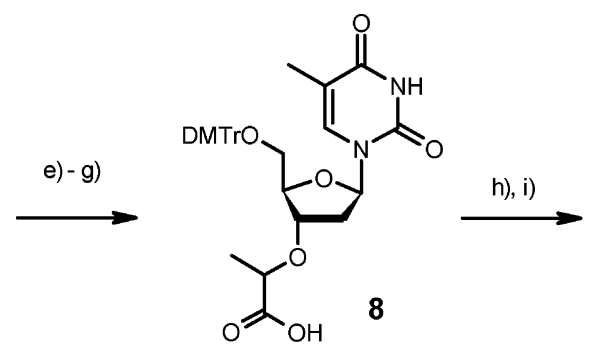

${ }^{a}$ (a) 1.2 equiv DMTr-Cl, pyridine, $3 \mathrm{~h}, \mathrm{rt}, 96 \%$. (b) 1.2 equiv BOM-Cl, 1.2 equiv DBU, $\mathrm{CH}_{3} \mathrm{CN}_{1} \mathrm{CH}_{2} \mathrm{Cl}_{2}, 1 \mathrm{~h}, 16-18{ }^{\circ} \mathrm{C}, 61 \%$. (c) 4.0 equiv $\mathrm{BrCH}\left(\mathrm{CH}_{3}\right) \mathrm{COO} t \mathrm{Bu}, \mathrm{Bu}_{4} \mathrm{NHSO}_{4}\left(0.5\right.$ equiv), $50 \% \mathrm{NaOH} /$ benzene $1: 1,1 \mathrm{~h}, 16-18{ }^{\circ} \mathrm{C} ;+0.6$ equiv BrCH$(\mathrm{CH}) \mathrm{COO} t \mathrm{Bu}, 1 \mathrm{~h}, 16-18{ }^{\circ} \mathrm{C} ;+0.6$ equiv $\mathrm{BrCH}\left(\mathrm{CH}_{3}\right) \mathrm{COO} t \mathrm{Bu}, 1 \mathrm{~h}, 16-18{ }^{\circ} \mathrm{C}, 74 \%$. (d) (1) 4 equiv TFA, $\mathrm{CH}_{2} \mathrm{Cl}_{2}, \mathrm{rt}, 1 \mathrm{~h}$; $+\mathrm{MeOH}$ (excess), 5 min, rt; (2) separation of diastereoisomers by flash chromatography, 7A: $50 \%, 7 \mathbf{B}: 31 \%$. (e) (1) 7B, $\mathrm{H}_{2}, 10 \%$ Pd-C, THF/MeOH 1:1, atm. pressure, $1 \mathrm{~h}, \mathrm{rt}$; (2) dioxane/aqueous $\mathrm{Na}_{2} \mathrm{CO}_{3} 3: 1$ ( 1 equiv $\mathrm{Na}_{2} \mathrm{CO}_{3}$ ), $4 \mathrm{~h}$, rt, $86 \%$. (f) 1.2 equiv DMTr-Cl, pyridine, $3 \mathrm{~h}, 0^{\circ} \rightarrow \mathrm{rt}, 93 \%$. (g) $2 \mathrm{~N} \mathrm{LiOH} / \mathrm{THF} / \mathrm{H}_{2} \mathrm{O} 1: 8: 1,16 \mathrm{~h}, 65^{\circ} \mathrm{C}, 84 \%$. (h) $(1) 1.1$ equiv TBTU, 1.1 equiv $\operatorname{EtN}(i \operatorname{Pr})_{2}$, DMF, rt, 5 min. (2) $+\mathbf{9}(22)$, rt, 2 h, $90 \%$. (i) 1.95 equiv $\left((i \mathrm{Pr})_{2} \mathrm{~N}\right)_{2} \mathrm{POCH}_{2} \mathrm{CH}_{2} \mathrm{CN}, 2.8$ equiv diisopropylammonium tetrazolide, $\mathrm{CH}_{2} \mathrm{Cl}_{2}, 90 \mathrm{~min}$, rt and $2 \mathrm{~h}, 40{ }^{\circ} \mathrm{C}, 56 \%$. (BOM-Cl, benzyloxymethyl chloride; TBTU, $O\left(1 H\right.$-benzotriazol-1-yl)- $N, N, N^{\prime}, N^{\prime}-$ tetramethyluronium tetrafluoroborate).

modifications, are compatible with high-affinity RNA binding. Moreover, we show that the RNA-binding affinity of modified oligonucleotides incorporating backbone linkages of the type $\mathrm{X}^{\prime}-\mathrm{C}^{*} \mathrm{H}\left(\mathrm{CH}_{3}\right)-\mathrm{CO}-\mathrm{NH}-\mathrm{CH}_{2}\left(\mathrm{X}=\mathrm{O}, \mathrm{CH}_{2}\right)$ depends on the absolute stereochemistry of the linker moiety.

\section{MATERIALS AND METHODS}

General Methods. All reagents and solvents were used as purchased, unless otherwise mentioned. Drying of all solvents was carried out following reported procedures (16). TLC was performed on Merck silica gel 60 F254 precoated plates. 2'Deoxynucleotide phosphoramidites and 3'-terminal nucleoside controlled-pore glass supports were purchased from Glen Research (Sterling, VA). All other chemicals for solid-phase oligonucleotide synthesis were also purchased from Glen Research (Sterling, VA).

Synthesis of Amide-Linked 5'-DMTr-Protected Dimer Phosphoramidite Units. The syntheses of amide-modified DMTr-protected dimer phosphoramidites $\mathbf{1 - 5}$ are summarized in Schemes 1 (1) and 2 (4) and in Schemes S1 (2), S2 (3), and S3 (5) in the Supporting Information. All 5'DMTr-protected 3'-CE phosphoramidites were characterized by ${ }^{1} \mathrm{H}$ - and ${ }^{31} \mathrm{P}$ NMR. On the basis of these analyses, all compounds employed for the synthesis of modified oligonucleotides were found to be $>95 \%$ pure. All synthetic procedures as well as NMR and MS data are provided in the Supporting Information.

Oligonucleotide Synthesis and Purification. All amidemodified oligonucleotides were synthesized on an ABI 381A DNA synthesizer with slight modifications to published procedures (17). Monomer coupling times were $90 \mathrm{~s}$ for 3'$\mathrm{CE}$ phosphoramidites and 10 min for amide amidites, with the oligomers synthesized with the $5^{\prime}$-terminal trityl group off. Deprotection and cleavage from the solid support were achieved by treatment with $28-30 \% \mathrm{NH}_{4} \mathrm{OH}$ at $55{ }^{\circ} \mathrm{C}$ for 8 $\mathrm{h}$. The sequences were analyzed and purified by strong anion exchange (SAX) chromatography on a Pharmacia AKTA Purifier HPLC instrument with a DIONEX DNAPac PA100 analytical column $(4 \times 25 \mathrm{~mm})$ purchased from DIONEX Corp. (Sunnyvale, CA). For preparative runs, 25 OD units were purified on the analytical column at a time with a gradient of $25 \mathrm{mM}$ tris(hydroxymethyl)aminomethane$\mathrm{HCl}(\mathrm{pH} 7.8)$ to $1 \mathrm{M} \mathrm{NaCl}$ over $30 \mathrm{~min}$ and a flow rate of

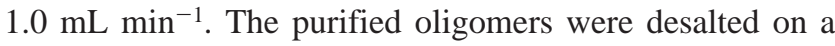
Sep-Pak cartridge (Waters Inc., Milford, MA). The cartridge was pre-equilibrated with acetonitrile followed by water. The oligonucleotide solutions were applied to the cartridge and washed with water, and a solution of $75 \%$ methanol in water was then used to elute the desalted oligomers with a final yield of $40-55 \%$. RNA oligonucleotides were purchased 
Scheme $2^{a}$
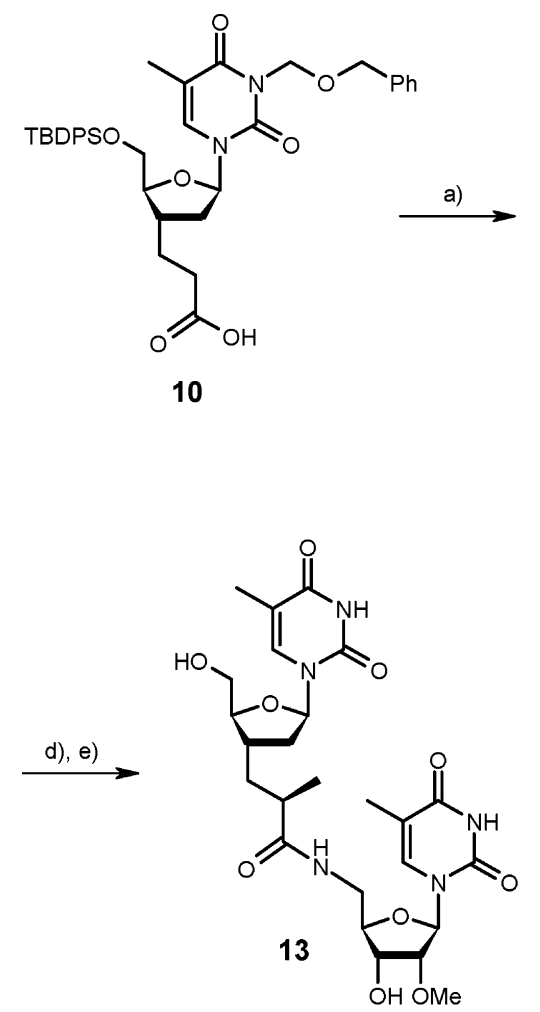
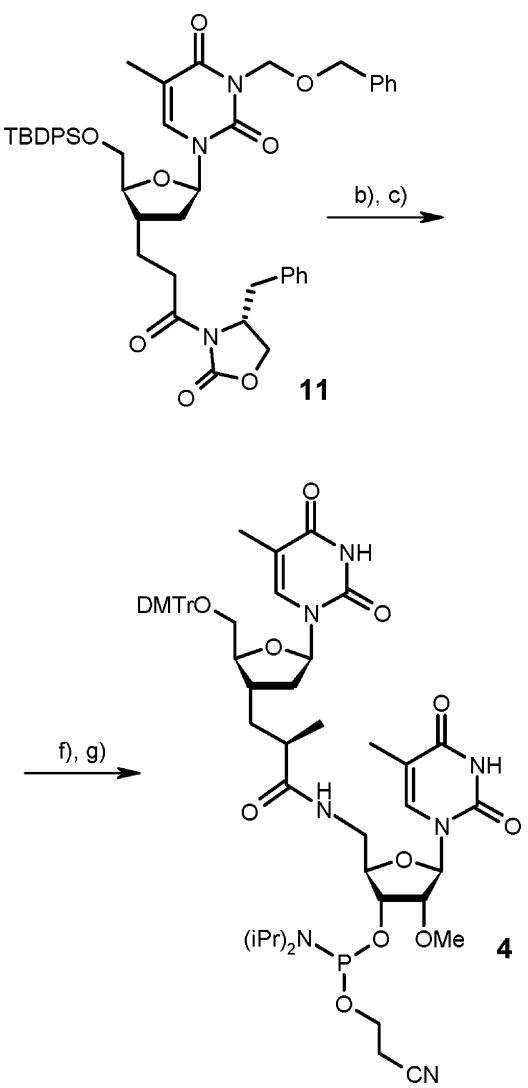<smiles>CCCCOCC1OC2CC1C[C@H](C(C)C(=O)O)O2</smiles>

12

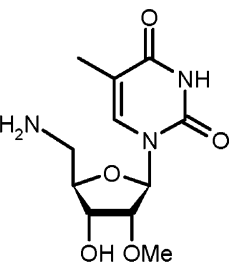

14

${ }^{a}$ (a) (1) 10 (13), 1.05 equiv Piv-Cl, 1.05 equiv $\mathrm{NEt}_{3}$, THF, $0{ }^{\circ} \mathrm{C}$; (2) 1.0 equiv (4R)-4-benzyl-oxazolidinone, 1.0 equiv n-BuLi, THF, $-78{ }^{\circ} \mathrm{C}$; $-78{ }^{\circ} \mathrm{C} \rightarrow \mathrm{rt}, 6 \mathrm{~h}, 60 \%$. (b) 1.2 equiv (TMS) $)_{2} \mathrm{NNa}, 5.0$ equiv MeI, THF, $3 \mathrm{~h},-78{ }^{\circ} \mathrm{C} \rightarrow \mathrm{rt}$, $75 \%$. (c) 2.0 equiv $\mathrm{LiOH} \times \mathrm{H}_{2} \mathrm{O}, 4.0$ equiv $\mathrm{H}_{2} \mathrm{O}_{2}(30 \%$ aq), THF/ $\mathrm{H}_{2} \mathrm{O}(3 / 1), 30 \mathrm{~min}, 0{ }^{\circ} \mathrm{C}$, quant. (d) 2.0 equiv TBTU, 1.0 equiv $\mathrm{HOBt}, 10$ equiv $\operatorname{EtN}(i \mathrm{Pr})_{2}, 1.0$ equiv 14 (24), DMF, $1.5 \mathrm{~h}, \mathrm{rt}, 88 \%$. (e) 0.2 equiv $\mathrm{Pd} / \mathrm{C}(10 \%), \mathrm{H}_{2}(1 \mathrm{~atm}), \mathrm{HCl} 37 \%$ aq/MeOH (1:10), $24 \mathrm{~h}, \mathrm{rt}, 89 \%$. (f) $3 \times 1.0$ equiv DMTr-Cl, pyridine, $4.5 \mathrm{~h}, \mathrm{rt}, 91 \%$. (g) 1.5 equiv $\left((i \mathrm{Pr})_{2} \mathrm{~N}\right)_{2} \mathrm{POCH}_{2} \mathrm{CH}_{2} \mathrm{CN}, 2.0$ equiv diisopropylammonium tetrazolide, $\mathrm{CH}_{2} \mathrm{Cl}_{2}, 16 \mathrm{~h}$, rt, 75\%. (TBTU, $O\left(1 H\right.$-benzotriazol-1-yl)- $N, N, N^{\prime}, N^{\prime}$ tetramethyluronium tetrafluoroborate; HOBt, 1-hydroxybenzotriazole; TBDPS, tert.-butyl-diphenylsilyl).

from DHARMACON, deprotected following the manufacturer's instructions, and purified using SAX chromatography.

Thermal Denaturation Studies. Absorbance versus temperature profiles were recorded at $260 \mathrm{~nm}$ on a CARY BIO-1 spectrophotometer equipped with a Peltier temperature control device. The measurements were conducted with all five amide-containing oligonucleotides complexed with the complementary RNA sequences. The wild-type RNA-DNA duplex under identical conditions served as the reference. The samples were prepared under sterile conditions in 0.01 $\mathrm{M}$ Tris- $\mathrm{HCl}$ buffer ( $\mathrm{pH} 7$ ) containing $0.15 \mathrm{M} \mathrm{NaCl}$ solution and were subsequently degassed. The measurements were carried out at $0.75,1.5,2.5,4.8$, and $9.2 \mu \mathrm{M}$ concentrations of the duplexes. Each sample was briefly heated to $70{ }^{\circ} \mathrm{C}$, cooled to room temperature in the heating block, and stored overnight at $4{ }^{\circ} \mathrm{C}$. The melting curves were obtained with a heating ramp of $0.5^{\circ} \mathrm{C} / \mathrm{min}$. The melting temperatures $T_{\mathrm{M}}$ were calculated by the differentiation of the melting curves, and the thermodynamic data were obtained according to Marky and Breslauer (18).

Circular Dichroism Studies. All spectra were recorded at $5{ }^{\circ} \mathrm{C}$ using a JASCO J-710 spectropolarimeter equipped with a Julabo heating/cooling system. The buffer used was 10 $\mathrm{mM}$ phosphate with a total sodium concentration of $100 \mathrm{mM}$ (supplemented as $\mathrm{NaCl}$ ), $10 \mathrm{mM}$ EDTA at $\mathrm{pH}$ 7.0. Following temperature equilibration, ellipticity data were collected for a $10 \mathrm{~s}$ period. The measurements were carried out with a total strand concentration of $2.5 \mu \mathrm{M}$ and are the average of 5 scans.

Crystallization, X-ray Data Collection and Refinement. Crystals were obtained for a 1:1 mixture of the DNA nonamer with the sequence $5^{\prime}$-TTCTamT ${ }^{\mathrm{Br}}$ CTTC (where TamT is the type IV modified dimer and ${ }^{\mathrm{Br}} \mathrm{C}$ is 5-bromodeoxycytidine) and the complementary RNA 5'-GAAGAAGAA at room temperature via the hanging-drop vapor diffusion method. A droplet containing $1 \mathrm{mM}$ duplex, 0.5 $\mathrm{mM}$ cobalt hexamine, $5 \mathrm{mM}$ spermine tetrachloride, $80 \mathrm{mM}$ sodium cacodylate buffer ( $\mathrm{pH} 7.0$ ), and 10\% (v/v) 2-methyl2,4-pentanediol (MPD) was equilibrated against a reservoir of $1 \mathrm{~mL}$ of $40 \% \mathrm{MPD}$. The space group was tetragonal $\mathrm{PH}_{3}$ with unit cell constants $a=b=47.23 \AA$ and $c=24.46 \AA$. A crystal was mounted on a nylon loop and frozen in liquid nitrogen. Diffraction data to $2.8 \AA$ resolution were collected at $120 \mathrm{~K}$ on the insertion device beamline (5-ID) of the Dupont-Northwestern-Dow Collaborative Access Team located at the Advanced Photon Source, Argonne National Laboratory, Argonne, Illinois. Data were integrated and scaled using the DENZO/SCALEPACK program suite (19). The structure was determined by molecular replacement with the program CNS (20), using an A-form duplex model and the location of the single bromine atom per duplex to verify validity of the model. Refinement of the structure was carried out with the program CNS using adapted topology and parameter files. The final $R$-work is $23.4 \%(R$-free $=27.1 \%)$ 


\begin{tabular}{ll}
\hline Table 1: Selected Crystal Data and Refinement Parameters \\
\hline sequence & $5^{\prime}$-d(TTC TamT ${ }^{\mathrm{Br}} \mathrm{C}$ TTC)-3' \\
& $3^{\prime}$-r(AAG AAG AAG)-5' \\
space group & tetragonal P4 4 \\
beam line & APS, DND-CAT 5-ID \\
detector & MARCCD 225 \\
temperature & $-160^{\circ} \mathrm{C}$ \\
unit cell constants $(\AA)$ & $a=b=47.23, c=24.46$ \\
resolution $(\AA)$ & 2.80 \\
number of unique reflections & 2388 \\
completeness $(20-2.80 \AA)(\%)$ & 99.9 \\
$R$-merge $(\%)$ & 7.0 \\
$R$-work $(\%)$ & 23.4 \\
$R$-free $(\%)$ & 27.1 \\
rmsd of bond lengths $(\AA)$ & 0.006 \\
rmsd of bond angles [deg.] & 1.30 \\
\hline
\end{tabular}

${ }^{a}$ The sequence contains a TamT dimer of type IV.

(21) for all 2388 reflections with $F_{\text {obs }} \geq 2 \sigma\left(F_{\text {obs }}\right)$ to $2.80 \AA$ resolution. Selected crystal data, data collection, and refinement parameters are listed in Table 1.

\section{RESULTS AND DISCUSSION}

Synthesis of 5'-O-DMTr-Protected Modified Dimer Phosphoramidites. The 5'-O-DMTr-protected 3'-phosphoramidite of the modified TamT dimer of type IA (1) was prepared starting from thymidine, which was first converted to its 5'$O$-DMTr-protected derivative (Scheme 1). Subsequent protection of $\mathrm{N} 3$ of the thymine base with a benzyloxymethyl (BOM) group gave 6, which was alkylated with bromopropionic acid tert-butyl ester under phase transfer conditions. Not too surprisingly, the reaction led to a mixture of diastereoisomers, which could not be separated at this stage. However, separation could be achieved after the removal of the $5^{\prime}-O$-DMTr-protecting group to provide pure isomers $7 \mathbf{A}$ and $\mathbf{7 B}$ in $37 \%$ and $23 \%$ yields, respectively (based on $\mathbf{6}$ ). The absolute stereochemistry of the two isomers is not known at this point. Both isomers were then separately transformed into the corresponding $5^{\prime}$ - $O$-DMTr-protected acids via the hydrogenolytic removal of the BOM group, followed by reprotection of the $5^{\prime}-\mathrm{OH}$ group as a DMTr ether and subsequent ester saponification. Yields shown in Scheme 1 are for the reaction sequence based on major isomer $\mathbf{7 B}$, which provided carboxylic acid $\mathbf{8}$. Elaboration of $\mathbf{8}$ into the desired phosphoramidite $\mathbf{1}$ was then straightforward and involved HBTU-mediated coupling with amino nucleoside 9 (22) and, finally, the conversion of the resulting dimer into the desired phosphoramidite under standard conditions.
The preparation of the 5'-O-DMTr-protected 3'-phosphoramidite of the modified TamT dimer of type III (4) initially involved the coupling of known carboxylic acid $\mathbf{1 0}$ (13) to $(R)$-4-benzyl-2-oxazolidinone employing the mixed anhydride method (Scheme 2). The resulting acyl-oxazolidinone $\mathbf{1 1}$ was then stereoselectively alkylated with $\mathrm{CH}_{3} \mathrm{I}$ to provide, after chromatographic purification, the diastereomerically pure $R$-alkylation product ( $R$-configuration at the newly formed chiral center) in $75 \%$ yield. The removal of the chiral auxiliary with LiOOH/THF (23) gave acid $\mathbf{1 2}$ (quantitative yield), which was coupled to amine 14 (24) using TBTU as the coupling agent. Catalytic hydrogenation of the resulting protected dimer in the presence of acid resulted in the simultaneous removal of the BOM- as well as the $5^{\prime}-O$-TBDPS-protecting group to give free dimer $\mathbf{1 3}$. DMTr-protection and phosphitylation under standard conditions finally provided the desired phosphoramidite 4 in $68 \%$ overall yield (based on 13).

Thermodynamic Stability of Heteroduplexes between RNA and DNAs Containing Five-Atom Amide Linkages. To determine the UV melting temperatures $T_{\mathrm{M}}$ and thermodynamic stabilities of amide-modified DNAs paired to RNA, two different oligodeoxynucleotide sequences were prepared, incorporating either one or five internucleoside amide linkages (sequences $\mathbf{A}$ and $\mathbf{B}$, respectively, Tables 2 and 3). In addition, sequence $\mathbf{C}$ was prepared, which contained a total of seven type IB modifications both at TT and $\mathrm{T}^{\mathrm{Me}} \mathrm{C}$ steps: 5'-TamTTamTTam ${ }^{M e} \mathrm{CTam}^{\mathrm{Me}} \mathrm{CTam}^{\mathrm{Me}} \mathrm{CTam}^{\mathrm{Me}} \mathrm{CTam}^{\mathrm{Me}}$ CT-3', where TamT and $\mathrm{Tam}^{\mathrm{Me}} \mathrm{C}$ represent modified dimer units (Table 2). All sequences were prepared by using $5^{\prime}$ DMTr-protected dimer phosphoramidites $\mathbf{1 - 5}$ and by following standard oligonucleotide synthesis protocols. RNAbinding affinity was assessed by the comparison of duplex stability between modified and unmodified (wild-type) RNA-DNA heteroduplexes. To determine the contribution of the 2'-methoxy substituent at the 3'-sugar in modified dimers of type IB-IV in duplexes with a single amide linkage to stability, an additional $15 \mathrm{mer}$ oligonucleotide was prepared on the basis of sequence A containing a 2'-OMe-T nucleoside at position 5 (Table 2). Similarly, to assess the influence on stability of 2 -methoxy modifications in duplexes with multiple amide linkages, additional reference oligonucleotides based on sequence $\mathbf{B}$ were prepared, which contained multiple T-2'-OMe-T, 2'-OMe-T-T, or 2'-OMeT-2'-OMe-T dimers (Table 3 ). The required RNA sequences 5'-ACACACACACAAAAA-3' (complementary to A) and

\begin{tabular}{|c|c|c|c|c|c|c|}
\hline $\begin{array}{c}\text { TamT unit } \\
(\text { modification type) })^{a}\end{array}$ & $\begin{array}{c}T_{\mathrm{M}} \\
\left({ }^{\circ} \mathrm{C}\right)^{b}\end{array}$ & $\begin{array}{c}\Delta T_{\mathrm{M}} / \mathrm{mod} . \\
\left({ }^{\circ} \mathrm{C}\right)^{b, c}\end{array}$ & $\begin{array}{c}-\Delta H^{\circ} \\
(\mathrm{kcal} / \mathrm{mol})^{d}\end{array}$ & $\begin{array}{c}-\Delta \mathrm{S}^{\circ} \\
(\mathrm{cal} / \mathrm{mol} \mathrm{K})^{d}\end{array}$ & $\begin{array}{c}-\Delta G_{310}^{\circ} \\
(\mathrm{kcal} / \mathrm{mol})^{d}\end{array}$ & $r^{2}$ \\
\hline DNA (dT-dT) & 53.4 & & 96.3 & 268.6 & 13.0 & 0.920 \\
\hline IA & 51.5 & -2.1 & 74.7 & 204.8 & 11.4 & 0.990 \\
\hline II & 54.0 & +0.5 & 99.2 & 277.2 & 13.2 & 0.994 \\
\hline III & 54.8 & +1.6 & 103.4 & 289.0 & 13.8 & 0.914 \\
\hline IV & 55.3 & +1.5 & 54.8 & 140.9 & 11.1 & 0.983 \\
\hline IB & 54.4 & +0.6 & 78.0 & 212.3 & 12.2 & 0.931 \\
\hline IB $\left.\left(\operatorname{TamT/Tam}{ }^{M e} C\right)\right)^{e}$ & 61.8 & +1.5 & 73.4 & 192.6 & 13.7 & 0.815 \\
\hline dT-2'OMe-rT & 54.4 & +0.9 & 85.2 & 233.8 & 12.7 & 0.979 \\
\hline
\end{tabular}

${ }^{a}$ DNA: $5^{\prime}$-TTT TamTC TCT CTC TCT-3' (A), RNA: 5'-AGA GAG AGA GAA AAA-3'. For modification types cf. Figure $1 .{ }^{b}$ At a total strand concentration of $4 \mu \mathrm{M}$ in $10 \mathrm{mM}$ phosphate buffer at $\mathrm{pH} 7.0$ with a total sodium concentration of $100 \mathrm{mM}$ (as $\mathrm{NaCl})$ and $10 \mathrm{mM}$ EDTA. ${ }^{c}$ Compared to all-DNA. ${ }^{d}$ On the basis of the results at five different oligonucleotide concentrations. ${ }^{e} 5^{\prime}-\operatorname{TamT~TamT~Tam~}^{\text {Me }} \mathrm{C} \operatorname{Tam}^{\mathrm{Me}} \mathrm{C} \operatorname{Tam}^{\mathrm{Me}} \mathrm{C}$ $\operatorname{Tam}^{\mathrm{Me}} \mathrm{C} \mathrm{Tam}^{\mathrm{Me}} \mathrm{C}$ T-3' (C), RNA 5'-AGA GAG AGA GAA AAA-3'. 


\begin{tabular}{|c|c|c|c|c|c|c|}
\hline TamT unit & $\begin{array}{c}T_{\mathrm{M}} \\
\left({ }^{\circ} \mathrm{C}\right)^{b}\end{array}$ & $\begin{array}{c}\Delta T_{\mathrm{M}} / \mathrm{mod} \\
\left({ }^{\circ} \mathrm{C}\right)^{b, c}\end{array}$ & $\begin{array}{c}-\Delta H^{\circ} \\
(\mathrm{kcal} / \mathrm{mol})^{d}\end{array}$ & $\begin{array}{c}-\Delta S^{\circ} \\
(\mathrm{cal} / \mathrm{mol} \mathrm{K})^{d}\end{array}$ & $\begin{array}{c}-\Delta G_{310}^{\circ} \\
(\mathrm{kcal} / \mathrm{mol})\end{array}$ & $r^{2}$ \\
\hline DNA (T-T) & 51.0 & & 88.1 & 245.8 & 11.9 & 0.923 \\
\hline IA & 42.1 & -1.8 & 76.8 & 217 & 9.5 & 0.998 \\
\hline II & 47.3 & -0.7 & 103.5 & 297 & 11.4 & 0.857 \\
\hline III & 54.0 & +0.6 & 71.3 & 192 & 11.8 & 0.959 \\
\hline IV & 52.0 & +0.2 & 73.8 & 201 & 11.5 & 0.966 \\
\hline $\mathrm{dT}-2^{\prime}-O \mathrm{Me}-\mathrm{T}$ & 48.2 & -0.6 & 92.3 & 261 & 11.4 & 0.966 \\
\hline $2^{\prime}-O \mathrm{Me}-\mathrm{T}-\mathrm{T}$ & 51.2 & +0.0 & 81.9 & 226 & 11.8 & 0.992 \\
\hline $2^{\prime} O \mathrm{Me}-\mathrm{T}-2^{\prime} O \mathrm{Me}-\mathrm{T}$ & 60.1 & +1.8 & 74.9 & 199 & 13.2 & 0.966 \\
\hline
\end{tabular}

${ }^{a}$ DNA: 5'-GCG TamT TamT TamT TamT TamT GCG-3' (B), RNA: $5^{\prime}$-CGC AA AA AA AA AA CGC-3'. ${ }^{b}$ At a total strand concentration of $4 \mu \mathrm{M}$ in $10 \mathrm{mM}$ phosphate buffer at $\mathrm{pH} 7.0$ with a total sodium concentration of $100 \mathrm{mM}$ (as NaCl) and $10 \mathrm{mM}$ EDTA. ${ }^{c}$ Compared to all-DNA. ${ }^{d}$ On the basis of the results at five different oligonucleotide concentrations.

5'-CGCAAAAAAAAAACGC-3' (complementary to B) were purchased from DHARMACON.

The incorporation of a single TamT dimer of type IB, II, III, or IV generally enhances RNA-DNA duplex stability (Table 2). Modifications IB, III, and IV lead to comparable gains in stability $\left(\Delta T_{\mathrm{M}} /\right.$ modification ca. $\left.1.5^{\circ} \mathrm{C}\right)$ compared to that of the unmodified wild-type duplex (RNA-DNA). In contrast, the incorporation of a single modified TamT dimer unit of type IA results in a decrease in $T_{\mathrm{M}}$ of ca. $2{ }^{\circ} \mathrm{C}$, but combining it with a $2^{\prime}$-methoxy modification at the $3^{\prime}$ sugar (IB, Figure 1) results in a net stabilizing effect (compared with that of RNA-DNA, Table 2). Apparently, the well-established favorable effect of a $2^{\prime}$-methoxy moiety on RNA-binding affinity (1) is maintained irrespective of the particular nature of the backbone (phosphate vs amide). It should be noted in this context that modifications IA and IB are stereochemically homogeneous, that is, the single diastereoisomers of modified TamT dimers were used for phosphoramidite preparation in both cases, with both being derived from the same carboxylic acid 8 (Scheme 1). As indicated above, the absolute stereochemistry of the chiral center within the internucleoside linker is not known at this point, but the isomer presented in this article has a significantly more favorable effect on RNA-DNA duplex stability than the one with the opposite stereochemistry at the critical carbon atom (data not shown). Interestingly, modification II, which features a $3^{\prime}$-methylene moiety combined with a $2^{\prime}$-methoxy modification of the $3^{\prime}$-sugar, gives only a modest gain in $T_{\mathrm{M}}$ of $0.5^{\circ} \mathrm{C}$. This is somewhat surprising because both sugars should be locked in a $\mathrm{C} 3^{\prime}$-endo conformation, thus preorganizing the modified dimer in the RNA A-form conformation. However, linker II lacks the methyl substituent that is present in all other five-atom-amide-based linkages studied here (Figure 1). Apparently, this methyl substituent contributes to duplex stability to an extent that can be similar to that of a $3^{\prime}$-methylene group (IB vs II, Figure 1 and Table 2 ). In comparison, the introduction of a $2^{\prime}$-methoxy substituent at the $3^{\prime}$-sugar boosts the $T_{\mathrm{M}}$ value by ca. $2.5^{\circ} \mathrm{C}$ when comparing those from modifications IA and IB. It is possible that the introduction of a $2^{\prime}$-substituent at the $3^{\prime}$ sugar affects the geometry of the $5^{\prime}$-sugar, and the $3^{\prime}$ methylene modification of the latter may simply push its conformational equilibrium further to the $\mathrm{C} 3$ '-endo side.

The data listed in Table 2 also show that the gain in RNAbinding affinity is of similar magnitude for sequences with a single TamT dimer of type IB (A) or multiple modified TamT and Tam $^{M e} \mathrm{C}$ dimer units (C) $\left(1.5\right.$ vs $0.6^{\circ} \mathrm{C} /$ modified dimer). This is remarkable, given the fact that sequence $\mathbf{C}$ features no fewer than seven modified dimer units that alternate with phosphate-linked unmodified DNA dimers and include both the TT and $\mathrm{T}^{\mathrm{Me}} \mathrm{C}$ steps. This observation is in line with the results from CD spectroscopic studies in solution (vide infra) and shows that the five-atom amide linker does not lead to significant changes in pairing geometry or stacking interactions. The thermodynamic data summarized in Table 2 also reveal an interesting difference in binding free energy between modifications III and IV. Modification III confers a more favorable $\Delta G$ for binding, which largely originates in a significantly higher enthalpic contribution compared to that for modification IV ( -103 vs $-55 \mathrm{kcal} / \mathrm{mol}$ ). Modification IV compares favorably in terms of the entropy term $(-289$ and $-141 \mathrm{cal} / \mathrm{mol} \mathrm{K}$ for modifications III and IV, respectively). Although it should be kept in mind that these data are based on a single modification in a single test sequence, it is tempting to speculate that the configuration of the chiral center located in the internucleoside linker affects RNA-binding affinity and that the increased affinity afforded by the methyl group in the $R$ configuration is enthalpy-based.

When multiple modified dimers are present, as in sequence $\mathbf{B}$, the changes in duplex stability observed for sequence $\mathbf{B}$ with modifications IA, II, III, and IV are similar to those observed upon the incorporation of a single modified dimer (on a per modification basis and as judged from the changes in melting temperatures compared to that of the native RNA-DNA duplex, Table 3). However, a detailed analysis of the data shows that the gain in $T_{\mathrm{M}}$ for modified TamT dimers of type III and IV ( $\Delta T_{\mathrm{M}} /$ modified dimer) is more modest for the more extensively modified analogues, whereas modification II in alternation with natural phosphate-linked dimer units actually results in a slight loss of stability. The reduction in $T_{\mathrm{M}}$ value observed for multiple modifications IA $\left(-1.8^{\circ} \mathrm{C} /\right.$ modified dimer $)$ is comparable to that seen in the case of sequence $\mathbf{A}$ with just a single IA linkage $(-2.1$ ${ }^{\circ} \mathrm{C}$ ). As expected, locking both sugars in a $\mathrm{C} 3^{\prime}$-endo conformation leads to a profound increase in $T_{\mathrm{M}}$ of $0.9{ }^{\circ} \mathrm{C}$ per modified nucleoside (corresponding to $1.8{ }^{\circ} \mathrm{C}$ per modified dimer unit!). This compares with reduced RNAbinding affinity $\left(\Delta T_{\mathrm{M}}=-0.6{ }^{\circ} \mathrm{C} /\right.$ modified dimer $)$ for duplexes incorporating an alternating arrangement of $2^{\prime}$ methoxy modified sugar units (within the background of an otherwise unmodified phosphodiester backbone) (Table 3). In contrast, the incorporation of five consecutive modified dimers of type III, which is also characterized by an alternating arrangement of $2^{\prime}$-methoxy-modified sugar units, leads to a significant increase in $T_{\mathrm{M}}$ of $0.6^{\circ} \mathrm{C} /$ modified dimer. 

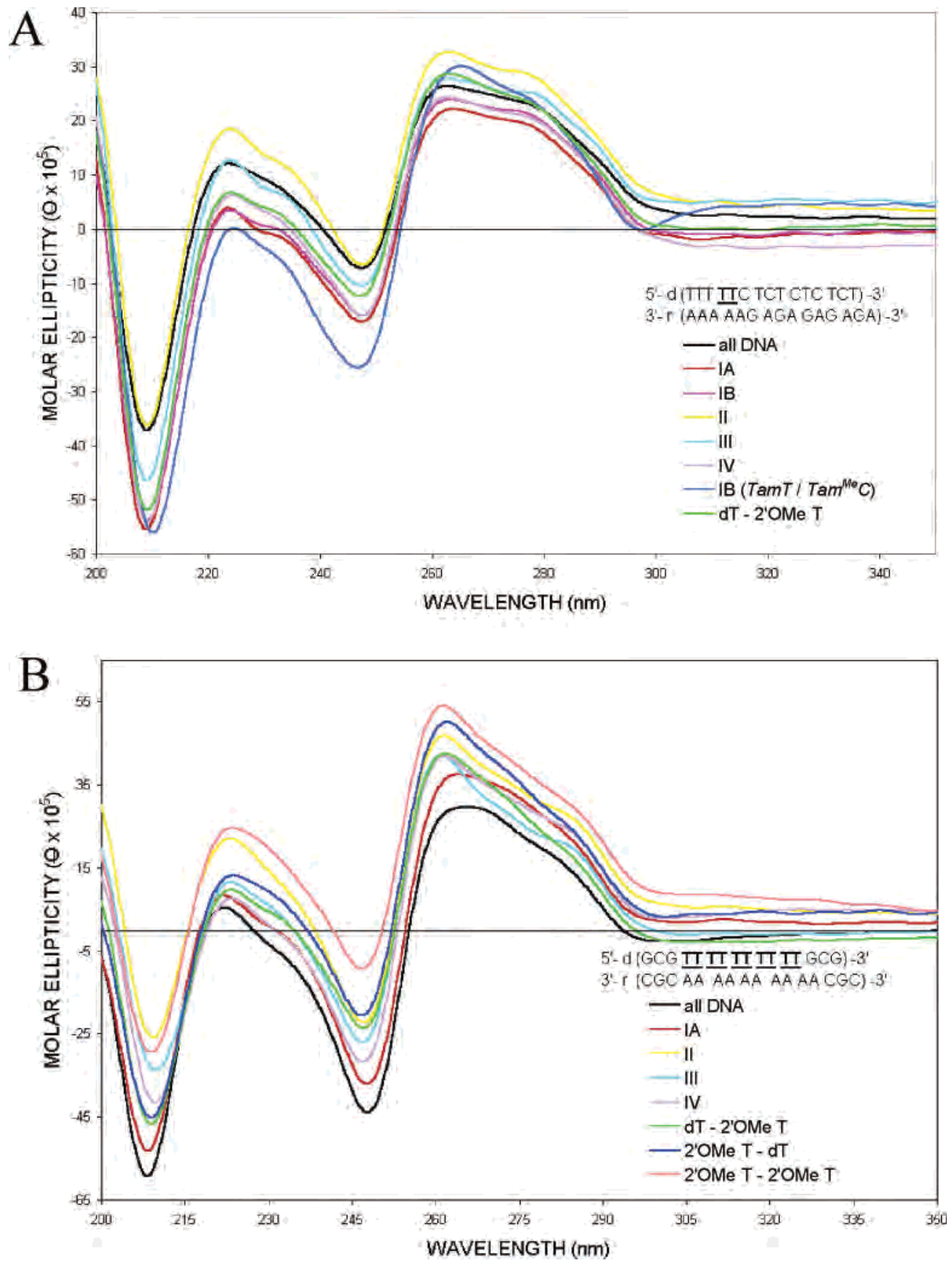

FIGURE 2: CD solution spectra for heteroduplexes with (A) single and (B) multiple amide-modified TamT dimers in the DNA strand. The dark blue line in A corresponds to sequence $\mathbf{C}$ with seven dimers of type IB.

This observation further highlights the stabilizing effect of the extended backbone linkage. Interestingly, modification III in the context of a highly modified sequence $\mathbf{B}$ now clearly exhibits a more favorable effect on RNA-binding affinity than modification IV on the basis of a $T_{\mathrm{M}}$ comparison. However, only small differences in binding free energy are observed between modifications II, III, and IV; likewise, an inspection of the $\Delta H$ and $\Delta S$ terms indicates no major differences in the relative contribution of enthalpic and entropic effects on binding free energy (Table 3). Nevertheless, on the basis of the observed differences in melting temperatures, it may be speculated that a linker moiety with $R$ configuration, as in modification III, has a more favorable effect on RNA-DNA duplex stability than the corresponding $S$-configured backbone modification (as in modification IV).
This may also indicate that the stereocenter in the internucleoside linkage present in modifications IA and IB is more likely to be $S$ - rather than $R$-configured (i.e., the methyl group in the structural representation in Figure 1 would also point upward, but because of a change in atom priority, this corresponds to an $S$-configuration of the chiral center).

Solution Structure of Amide-Modified RNA-DNA Duplexes. The CD spectra of amide-modified duplexes reveal only subtle differences from those of the wild type RNADNA duplex (Figure 2), indicating that the five-atom amide linkages in the DNA strand cause only a small change in the global conformation of the duplex. All duplexes have signatures that are consistent with an A-type structure with a large positive $\mathrm{CD}$ band around $260 \mathrm{~nm}$ and a large negative band centered at ca. $210 \mathrm{~nm}(25)$. These results are perhaps 
surprising because one would have assumed the planarity of the amide moiety in combination with the presence of an additional backbone atom in the type I to IV linkers to result in local perturbations of the duplex geometry.

Crystal Structure of an RNA-DNA Duplex with a Single Type IV TamT Dimer in the DNA Portion. To gain further insight into the origins of the duplex-stabilizing effects of modified dimers of type III or IV upon incorporation into the DNA strand of a RNA-DNA duplex, we set out to determine crystal structures of heteroduplexes containing single modified dimers in the DNA strand. To this end, we prepared modified oligodeoxyribonucleotides with the sequence $5^{\prime}-\mathrm{d}\left(\mathrm{TTCT} T \mathrm{Tm} T^{\mathrm{Br}} \mathrm{CTTC}\right)$, where TamT is a modified dimer either of type III or of type IV, and ${ }^{\mathrm{Br}} \mathrm{C}$ is 5-bromodeoxycytidine. The bromine was incorporated to facilitate the phasing of the structure. This particular RNA-DNA hybrid was selected because a crystal structure for the native duplex had been reported at $1.8 \AA$ resolution (26). The DNA strand of the latter duplex also featured ${ }^{\mathrm{B}}{ }^{\mathrm{Br}} \mathrm{C}$ in place of $\mathrm{C}$ at position 6 , and the structure can thus serve as a reference to which amide-modified duplexes can be compared. Crystals for hybrid duplexes containing either modification III or IV in the DNA strand could be grown, but the former diffracted only to low resolution (> $3.2 \AA$ ), and the data were not further considered. Crystals of the hybrid duplex with the type IV modification also diffracted to a lower resolution than those of the reference duplex but nevertheless proved to be suitable for structure determination (Table 1). An analysis revealed a tetragonal space group, whereas the crystals of the native nonamer duplex belong to space group $P 6_{1}$ (hexagonal). An inspection of the packing interactions in the reference structure shows that close contacts between neighboring molecules mostly affect the DNA strand (26). The terminal base pair of a symmetry related duplex stacks against sugars in the central portion of the DNA. Because this is the location of the amide linker in the backbone, it is not surprising that the symmetries and lattice interactions differ for crystals of the modified and native RNA-DNA duplexes.

The structure of the duplex with the type IV TamT dimer was determined by molecular replacement and refined using standard constraint least-squares procedures combined with simulated annealing and manual rebuilding. The location of bromine was used as a reference for examining the validity of the model. Both trans and cis isomeric forms of the amide linker were built into the model and subjected to refinement. Although the resolution of the data are rather limited, the trans orientation had a better fit with the omit electron density and also resulted in lower $R$-factors than the models with a cis conformation of the amide moiety. Final refinement parameters are listed in Table 1 , and an example of the quality of the Fourier $\left(2 F_{\mathrm{o}}-F_{\mathrm{c}}\right)$ sum electron density in the region of the modification is shown in Figure 3. The 3 '-terminal nucleotide of the RNA strand exhibited disorder and was refined with alternative conformations.

As expected, the amide-modified duplex adopts an overall A-form geometry with all sugars in the $\mathrm{C}^{3}$ '-endo conformation (Figure 4). An analysis of the helical parameters with the program CURVES (27) for both the native and the modified duplex reveals only minor differences (complete listing files of the CURVES runs are available as part of the Supporting Information). For example, the rise at the amide-

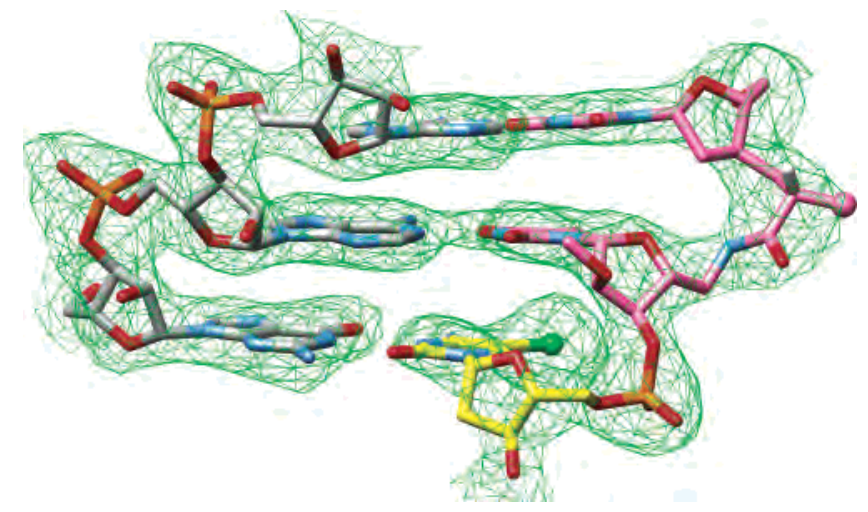

FIGURE 3: Quality of electron density. Final $\left(2 F_{\mathrm{o}}-F_{\mathrm{c}}\right)$ Fourier sum electron density at the $1 \sigma$ level around the central portion (bold) of the duplex 5'-d(TTC Tam $^{\mathrm{Br}} \mathbf{C}$ TTC): 5'-r(GAA GAA GAA). Carbon atoms of the RNA strand, DNA strand, and type IV linker are colored gray, yellow, and pink, respectively. The methyl carbon in the amide linker and the 5-bromine atom (green) are drawn as spheres, and the hydrogen atom at the chiral center in the amide linker is highlighted in white.

modified base-pair step (global inter-base pair parameter) is $3.05 \AA$ compared to $2.90 \AA$ in the reference duplex, whereas the helical twist at that step in the modified and reference duplexes is $29^{\circ}$ and $34^{\circ}$, respectively. Likewise, no significant deviations are observed for other geometric parameters, such as shift, slide, and roll. The global axis curvatures calculated with CURVES indicate a slightly more pronounced helical bend for the amide-modified duplex. This is visible from the deviating orientations of the RNA portion in the superimposition of the central portions in the modified and reference duplexes (Figure 5, upper right; also note the deviation between the helical axis of the modified duplex (green) and the reference duplex (magenta)). However, as is evident from the superimposition, the region of the nonnatural linker exhibits the most notable deviation, whereas the base-stacking interactions are virtually unaffected. Thus, neither different packing modes nor the presence of the fiveatom amide linker in the backbone result in a drastically altered geometry of the modified duplex compared to that of the reference structure. This is fully consistent with the stabilizing effects found for both the type III and IV modifications in the thermodynamic analyses (Tables 2 and 3).

The amide linker as such, that is, $\left(\mathrm{C}^{\prime}\right)-\epsilon-\mathrm{CH}_{2}-\xi-\underline{\mathbf{C}} \mathrm{H}^{*}-$ $\left(\mathrm{CH}_{3}\right)-\mathbf{C O}-\mathbf{N H}-\beta-\mathbf{C H}_{2}-\gamma-\left(\mathrm{C}^{\prime}\right)$, adopts a trans orientation with the atoms that are bold faced and underlined lying in the same plane. (The chiral center is marked by an asterisk.) We have labeled backbone torsion angles in the linker using the nomenclature for equivalent torsions in the DNA and RNA backbones (see above) (28). The backbone torsion angle $\epsilon$ (around the $\mathrm{C}^{\prime}-\mathrm{CH}_{2}$ bond) of the $5^{\prime}-\mathrm{T}$ in the TamT dimer is reduced to $97^{\circ}$ from its preferred antiperiplanar orientation in both $\mathrm{A}$ - and B-form duplexes (Figure 5). Torsion angles $\zeta$ (around $\mathrm{CH}_{2}-\mathrm{CH}^{*}$ ) and $\beta$ (around $\mathrm{N}-\mathrm{C}^{\prime}$ ) are $82^{\circ}$ and $88^{\circ}$, respectively. Torsion angle $\gamma$ (around $\mathrm{CH}_{2}-$ $\mathrm{C}^{\prime}$ ) of the $3^{\prime}-\mathrm{T}$ in the dimer is $169^{\circ}$ and thus lies in the range associated with an extended backbone variant of A-form DNA and RNA duplexes. In the crystallographic model, the carbonyl group of the amide moiety faces the minor groove, and the methyl substituent is directed away from the duplex (Figure 5). The structure allows no firm conclusions regarding a potential role of the solvent in the 

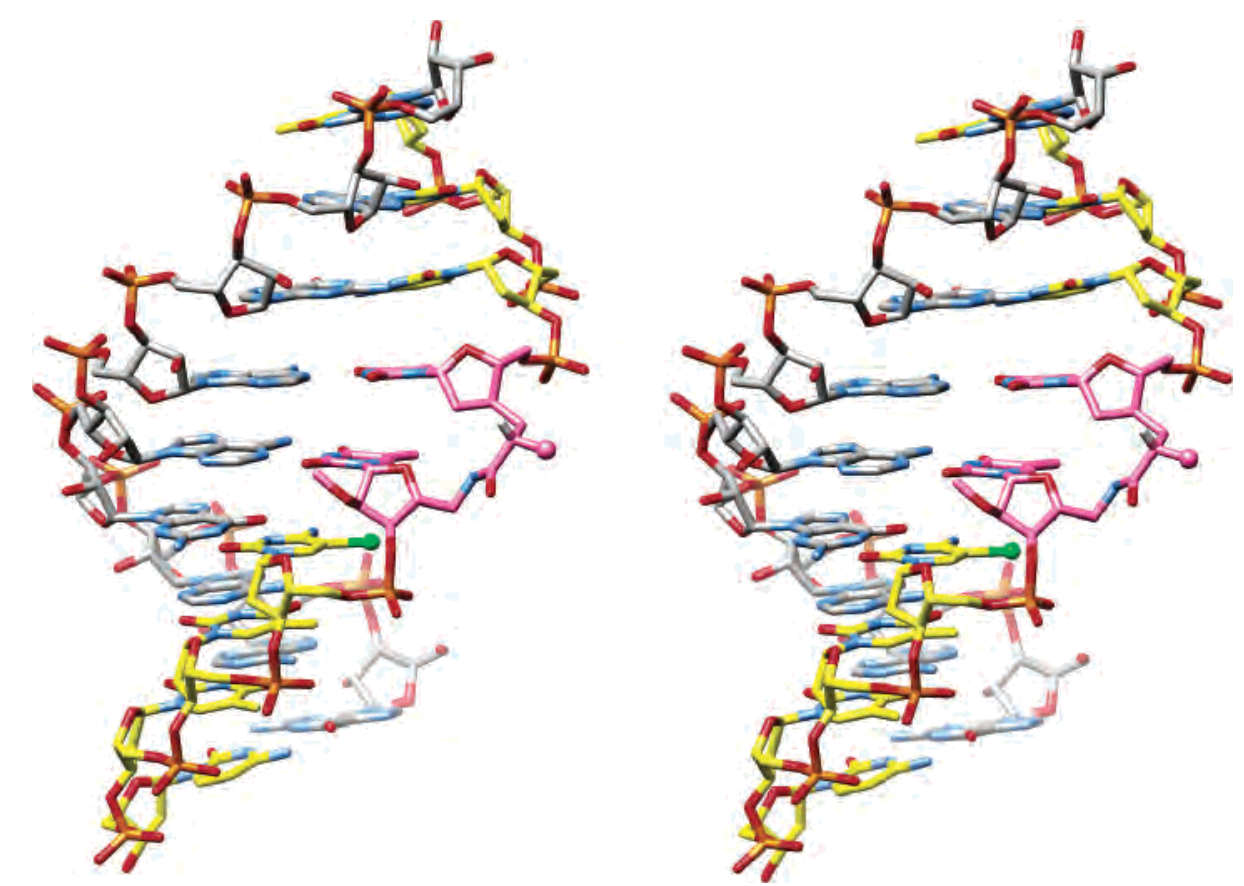

FIGURE 4: Stereo diagram of the duplex $5^{\prime}$-d(TTC $\operatorname{Tam}^{\mathrm{Br}} \mathrm{C}$ TTC): $5^{\prime}-\mathrm{r}(\mathrm{GAA}$ GAA GAA). The color code is identical to that in Figure 3 , and the view is across the major (top) and minor grooves (bottom).

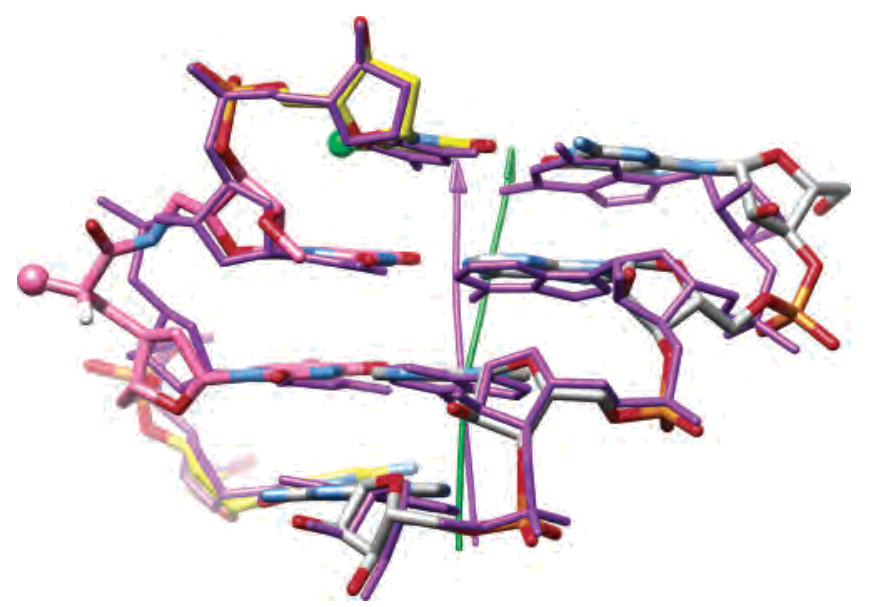

FIGURE 5: Superimposition of the RNA-DNA duplex with the type IV linker in the DNA strand (for color code, see Figure 3) and the reference duplex with the identical sequence (magenta bonds) (26). The orientations of the global helical axes calculated with the program CURVES (27) are shown as arrows (green, for the amide IV-modified duplex and magenta, for the reference duplex).

stability increases as a result of the amide modification because the current model includes only a limited number of water molecules (17). It is possible that an $R$-configuration of the methyl substituent (modification III) would lead to closer contacts between the methyl group and the sugar moiety of the 5'-T (Figure 5). However, it is likely that the amide linkers in type III and type IV modifications, with either $R$ - or $S$-configurations, respectively, of the chiral center (Figure 1E, F) will adopt slightly different overall conformations. This renders the predictions as to the relative orientation of methyl group and the 3 -methylene- 2 -deoxyribose of the $5^{\prime}-\mathrm{T}$ in the TamT dimers difficult. However, the different enthalpic and entropic contributions seen in the thermodynamic analyses of duplexes containing single type III or type IV dimer units (Table 2) may be related to alternative orientations of the methyl group relative to the sugar of the $5^{\prime}$-residue as well as the carbonyl moiety of the amide linker.

\section{CONCLUSIONS}

Our analysis of the thermodynamic stabilities of RNADNA duplexes containing single or multiple TamT (or $\operatorname{Tam}^{\mathrm{Me}} \mathrm{C}$ ) dimers with an extended amide-based linker in the DNA portion shows that, provided the extended backbone is combined with a $2^{\prime}$-methoxy group at the $3^{\prime}$-sugar moiety, the analogues exhibit only slightly lower stability compared with that of native RNA-DNA. Remarkably, amide-based linkers with an additional methyl substituent in the $R$ - or $S$-configurations adjacent to the $3^{\prime}$-methylene (in place of $\mathrm{O}^{\prime}$ ) of the $5^{\prime}$-sugar display modest enhancements of stability. However, the stability increases are clearly lower than those resulting from the 2 -methoxy modification at every ribo-T residue. Nevertheless, the finding that a DNA analogue with a five-atom linker between adjacent sugar moieties forms duplexes with RNA that are more stable than wild-type RNA-DNA duplexes is intriguing. Cross-pairing between RNA and analogues featuring shorter backbones (by one atom per residue) has previously been reported $(8-11)$. However, to the best of our knowledge, amide modifications of type IB, III, and IV are the only examples of nucleic acid analogues with a longer backbone that lead to a gain in RNA affinity. Because an earlier investigation of the pairing properties of analogues containing a variety of extended 5-atom internucleoside linkers, including amines and formacetals, found that an amide backbone resulted in the smallest loss of RNA affinity relative to DNA (12), our observations further underscore the unique properties of amide moieties in the backbones of nucleic acid analogues.

\section{ACKNOWLEDGMENT}

We would like to thank Dr. George Minasov for help with data collection and processing and Dr. Valentina Tereshko 
for assistance with the preparation of the crystallographic parameter and topology files for amide-modified oligonucleotides.

\section{SUPPORTING INFORMATION AVAILABLE}

Experimental section for all chemical syntheses, Schemes S1, S2, and S3 detailing the synthetic preparation of dimer phosphoramidite building blocks $\mathbf{2}, \mathbf{3}$, and 5, respectively, and CURVES outputs with helical parameters based on the crystal structures of both the native and modified duplexes. This material is available free of charge via the Internet at http://pubs.acs.org.

\section{REFERENCES}

1. Freier, S. M., and Altmann, K.-H. (1997) The ups and downs of nucleic acid duplex stability: structure-stability studies on chemically-modified DNA:RNA duplexes, Nucleic Acids Res. 25, 4429-4443.

2. De Mesmaeker, A.; Haener, R.; Martin, P., and Moser, H. E. (1995) Antisense oligonucleotides, Acc. Chem. Res. 28, 366-374.

3. De Mesmaeker, A., Altman, K.-H., Waldner, A., and Wendeborn, S. (1995) Backbone modifications in oligonucleotides and peptide nucleic acid systems, Curr. Opin. Struct. Biol. 5, 343-355.

4. Nielsen, P. E., Egholm, M., Berg, R. H., and Buchardt, O. (1991) Sequence-selective recognition of DNA by strand displacement with a thymine-substituted polyamide, Science 254, 1497-1500.

5. Bolli, M., Litten J. C., Schutz, R., and Leumann, C. J. (1996) Bicyclo-DNA: a Hoogsteen-selective pairing system, Chem. Biol. 3, 197-206.

6. Beigelman, L., Karpeisky, A., and Usman, N. (1995) Synthesis of 5'-C-methyl-D-allo- and L-talo-ribonucleoside 3'-O-phosphoramidites and their incorporation into hammerhead ribozymes, Nucleosides Nucleotides 14, 901-905.

7. Eschenmoser, A. (1999) Chemical etiology of nucleic acid structure, Science 284, 2118-2124.

8. Schöning, K. U., Scholz, P., Guntha, S., Wu, X., Krishnamurthy, R., and Eschenmoser, A. (2000) Chemical etiology of nucleic acid structure: the $\alpha$-threofuranosyl- $\left(3^{\prime} \rightarrow 2^{\prime}\right)$ oligonucleotide system, Science 290, 1347-1351.

9. Schöning, K. U., Scholz, P., Wu, X., Guntha, S., Delgado, G., Krishnamurthy, R., and Eschenmoser, A. (2002) The $\alpha-\mathrm{L}-$ threofuranosyl-( 3 ' $\rightarrow 2$ ')-oligonucleotide system ('TNA'): synthesis and pairing properties, Helv. Chim. Acta 85, 4111-4153.

10. Reck, F., Wippo, H., Kudick, R., Bolli, M., Ceulemans, G., Krishnamurthy, R., and Eschenmoser, A. (1990) L- $\alpha$-Lyxopyranosyl ( $\left.4^{\prime} \rightarrow 3^{\prime}\right)$ oligonucleotides: a base-pairing system containing a shortened backbone, Org. Lett. 1, 1531-1534.

11. Zhang, L., Peritz, A., and Meggers, E. (2005) A simple glycol nucleic acid, J. Am. Chem. Soc. 127, 4174-4175.

12. Stork, G., Zhang, C., Gryaznov, S., and Schultz, R. (1995) Modified oligonucleotides. Effect of 4- vs 5-atom chimeric internucleoside linkages on duplex stability, Tetrahedron Lett. 36 , 6387-6390.

13. De Mesmaeker, A., Jouanno, C., Wolf, R. M., and Wendeborn, S. (1997) Replacement of the phosphodiester linkage in oligo- nucleotides by an amide: effect of backbone length on duplex stability with RNA complement, Bioorg. Med. Chem. Lett. 7, 447-452.

14. De Napoli, L., Iadonisi, A., Montesarchio, D., Varra, M., and Piccialli, G. (1995) Synthesis of thymidine dimers containing a new internucleosidic amide linkage and their incorporation into oligodeoxyribonucleotides, Bioorg. Med. Chem. Lett. 5, 16471652.

15. Wilds, C. J., Minasov, G., von Matt, P., Altmann K.-H., and Egli, M. (2001) Studies of a chemically modified oligodeoxynucleotide containing a 5-atom amide backbone which exhibits improved binding to RNA, Nucleosides, Nucleotides Nucleic Acids 20, 991994.

16. Armarego, W. L. F., and Perrin, D. D., (Eds.) (1996) Purification of Laboratory Chemicals, Butterworth-Heineman, The Bath Press, Bath, U.K.

17. Wilds, C. J., and Damha, M. J. (2000) $2^{\prime}$-Deoxy-2'-fluoro- $\beta$-Darabinonucleosides and oligonucleotides ( $2^{\prime}$ F-ANA): synthesis and physicochemical studies, Nucleic Acids Res. 28, 3625-3635.

18. Marky, L. A., and Breslauer, K. J. (1987) Calculating thermodynamic data for transitions of any molecularity from equilibrium melting curves, Biopolymers 26, 1601-1620.

19. Otwinowski, Z., and Minor, W. (1997) Processing of X-ray diffraction data collected in oscillation mode, Methods Enzymol. 276, 307-326.

20. Brünger, A. T., Adams, P. D., Clore, G. M., DeLano, W. L., Gros, P., Grosse-Kunstleve, R. W., Jiang, J. S., Kuszewski, J., Nilges, M., Pannu, N. S., Read, R. J., Rice, L. M., Simonson, T., and Warren, G. L. (1998) Crystallography \& NMR System: a new software suite for macromolecular structure determination, Acta Crystallogr., Sect. D 54, 905-921.

21. Brünger, A. T. (1992) Free R value: a novel statistical quantity for assessing the accuracy of crystal structures, Nature 355, 472475.

22. Sproat, B. S., Beijer, B., and Rider, P. (1987) The synthesis of protected $5^{\prime}$-amino-2', $5^{\prime}$-dideoxyribonucleoside-3'-O-phosphoramidites; applications of $5^{\prime}$-amino-oligodeoxyribonucleotides, $\mathrm{Nu}$ cleic Acids Res. 15, 6181-6196.

23. Evans, D. A., Britton, T. C., and Ellman, J. A. (1987) Contrasteric carboximide hydrolysis with lithium hydroperoxide, Tetrahedron Lett. 28, 6141-6144.

24. Peterson, M. A., Nilsson, B. L., Sarker, S., Doboszewski, B., Zhang, W., and Robins, M. J. (1999) Amide-linked ribonucleoside dimers derived from 5'-amino-5'-deoxy- and 3'-(carboxymethyl)3'-deoxynucleoside precursors, J. Org. Chem. 64, 8183-8192.

25. Hung, S.-H., Yu, Q., Gray, D. M., and Ratliff, R. L. (1994) Evidence from CD spectra that d(purine).r(pyrimidine) and $\mathrm{r}$ (purine).d(pyrimidine) hybrids are in different structural classes, Nucleic Acids Res. 22, 4326-4334.

26. Xiong, Y., and Sundaralingam, M. (1998) Crystal structure and conformation of a DNA-RNA hybrid duplex with a polypurine RNA strand: d(TTCTTBr ${ }^{5}$ CTTC)-r(GAAGAAGAA), Structure 6, 1493-1501.

27. Lavery, R., and Sklenar, H. (1989) Defining the structure of irregular nucleic acids: conventions and principles, J. Biomol. Struct. Dyn. 6, 655-667.

28. Saenger, W. (1984) Principles of Nucleic Acid Structure, SpringerVerlag, New York.

BI0603540 